\title{
Paralimbic scleromalacia
}

\section{Spontaneous scleral intercalary perforation}

\author{
J. M. GAPPIN AND D. W. ALLEN \\ Moorfields Hospital, City Road, London
}

Spontaneous iris prolapse is a rare occurrence. Trauma, accidental or surgical, is the commonest cause of iris prolapse, but it may also be seen in a variety of conditions producing tissue destruction at the limbus. This is a report of a patient who presented with iris prolapse, but with no known predisposing lesion, resembling the condition described as "paralimbic or intercalary scleromalacia" by Franceschetti and Bischler (1950), who distinguished it from scleromalacia perforans and necrotizing scleritis. Although systemic associations are characteristically absent in the sixteen cases which have so far been reported, a patient of Zygulska-Machowa and Osterczy-Sliwińska (I969) resembled ours in having latent syphilis.

\section{Case report}

A man aged 74 years had been aware of a black area at the upper limbus of the right eye since the age of 20 years. He sustained no ocular injuries and had been exposed to no occupational ocular hazards. The black area remained constant for several years before slowly enlarging to become a distinct cyst. He had never experienced ocular pain or observed inflammation of the eye, but during the last 18 months the visual acuity had deteriorated. Apart from a duodenal ulcer (which had healed on medical treatment), his general health had always been satisfactory; in particular, he had never suffered joint or skin affections nor could he give a history of exposure to venereal disease.

\section{Examination}

The visual acuity in the right eye was reduced to perception of light with excellent projection. A large black cyst was present at the right upper limbus with a crystalline deposit (isomorphous with cholesterol) in the stroma of the corneal edge at its base (Figure, overleaf).

The cornea and sclera were otherwise normal.

The cyst was observed to consist of an outer wall of conjunctiva lined with uveal tissue continuous with the iris. The pupil was drawn upwards and gonioscopy revealed a limbal opening with the iris pillars projecting into it. No foreign bodies were seen in the anterior chamber on direct slitlamp or gonioscopic examination. No synechiae were present and the eye was quiet. The right lens had become densely cataractous. The intraocular pressure on applanation was io $\mathrm{mm}$. $\mathrm{Hg}$ right eye and i $\mathrm{mm}$. $\mathrm{Hg}$ left.

The left eye was normal except for the presence of arcus senilis and early peripheral cortical lens opacities.

\section{General examination}

There was no evidence of systemic disease. 


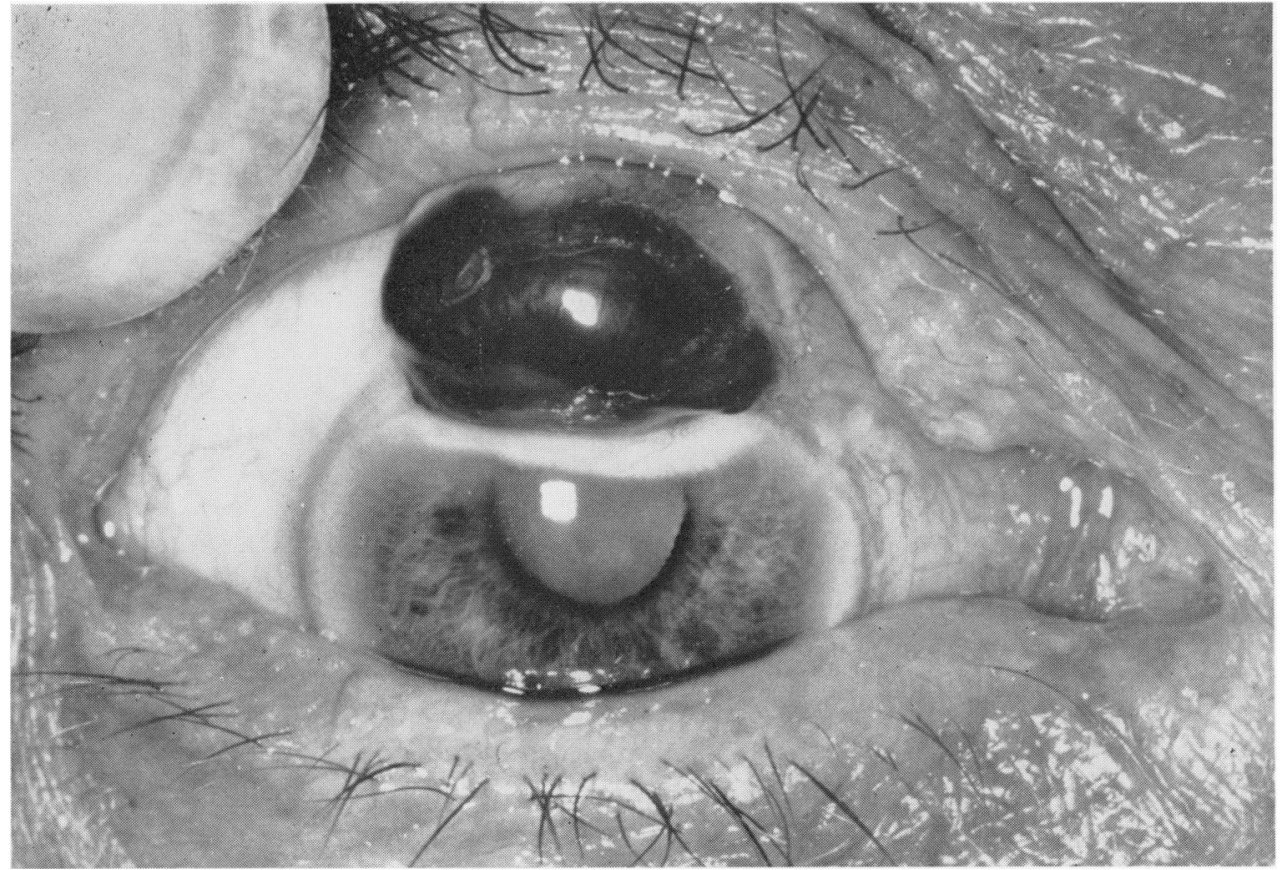

Figure Right eye. Anterior view showing iris prolapse

Investigations

No intraocular foreign bodies were detected radiologically. Chest $x$ ray, haematological investigations, and urine examination showed no abnormalities. The erythrocyte sedimentation rate was Io $\mathrm{mm}$./ $\mathrm{ist} \mathrm{hr}$ and the latex test was negative.

The results of the serological tests, however, were as follows:

Cardiolipin Wassermann reaction-Positive

VDRL_Positive at a dilution of only I : 2

FTA (ABS)-Positive

Reiter protein complement-fixation and Treponema pallidum immobilization tests-Both negative.

\section{Operative technique}

The cyst and adherent iris were excised. A lamellar scleral flap was dissected with its attached base nasally, rotated downwards to cover the limbal defect, and secured with four virgin silk sutures. A bridge conjunctival flap was fashioned and moved down to cover the scleral flap and limbus. Subconjunctival soframycin Ioo $\mathrm{mg}$. was administered on completion of the operation.

We should like to thank Mr. J. Ayoub for permission to publish this case and for his helpful comments.

\section{References}

Franceschetti, A., and Bischler, v. (1950) Ann. Oculist. (Paris), 183, 737

zygulska-maGhowa, H., and osterczy-SLIWińska, J. (1969) Klin. Oczna, 39, 623 